\title{
IVIG for Thymoma-Associated Pseudo-Obstruction: Report of Successful Treatment
}

\author{
David L. Greenburga Clifton C. Mo ${ }^{a}$ Paul A. Hemmer ${ }^{b}$ \\ a United States Army, Walter Reed Army Medical Center, Washington, D.C., ${ }^{b}$ United States Air Force, \\ Uniformed Services University of the Health Sciences, Bethesda, Md., USA
}

Dear Sir,

We report the case of a 36-year-old white male from rural Alaska with severe idiopathic gastroparesis and intolerance to oral nutrition who was referred to our institution. His primary concern was for his gastrointestinal symptoms which included abdominal fullness, nausea, vomiting, and stools as infrequent as every 3 weeks. Other symptoms over the preceding 7 months included intermittent diplopia, dysgeusia, and sicca symptoms. Radiologic evaluations including chest and abdominal plain films, CT scans of the sinuses, abdomen, pelvis, and MRI of the brain had been normal. A radionucleotide gastric emptying study showed $100 \%$ of the radiotracer retained in the stomach at $90 \mathrm{~min}$. EGD and colonoscopy were notable only for mild gastritis without evidence of Helicobacterpylori. Repetitive peripheral nerve stimulation testing and an extensive laboratory evaluation were normal. Therapies for his GI symptoms, including histamine blockers and osmotic and stimulant laxatives, were minimally effective. He lost over $50 \mathrm{lb}$ and required multiple admissions for intravenous fluids and parenteral nutrition.

The opinions expressed in this article represent those of the authors and do not reflect the opinions of the Department of Defense or the Uniformed Services University.
At our institution ophthalmology, neuro-ophthalmology, neurology, and gastroenterology consults were initiated. A radionucleotide gastric emptying study confirmed complete immotility. Evaluation of diplopia with prism testing revealed fluctuating levels of exotropia and hypertropia in the left eye. CT of the chest, abdomen, and pelvis revealed a $6 \times 6 \times 3 \mathrm{~cm}$ anterior mediastinal mass which was found to be a stage 1 thymoma. His postoperative course was complicated by a hemothorax and hypotension. Cosyntropin stimulation testing on postoperative day 1 revealed relative adrenal insufficiency for which he received intravenous hydrocortisone $100 \mathrm{mg}$ three times per day for 7 days. His symptoms persisted postoperatively and he continued to require parenteral fluids and nutrition. Results of a gastric emptying examination on postoperative day 11 were unchanged. Repeat prism testing after IM injection of neostigmine $1.5 \mathrm{mg}$ and atropine $2 \mathrm{mg}$ resulted in mild improvement in ocular discordance. Pyridostigmine 60 mg every $8 \mathrm{~h}$ was started. The only improvement after 2 days was a mild reduction in diplopia.

We believed our patient had thymomaassociated pseudo-obstruction. This was first reported in 1983 in a patient presenting with altered mental status and antibodies against the nicotinic acetylcholine receptor (N-AChR) [1]. Thymectomy can be a successful treatment for pseudo-obstruction, but recovery as late as 6 months after surgery has been reported [2-4]. Anderson et al. [5] described 2 cases of pseudo-obstruction, diplopia, dysgeusia, and antibodies against N-AChR who underwent thymectomy followed by pyridostigmine. Pseudo-obstruction resolved rapidly in one patient, but the second patient required resection of an immotile segment of duodenum prior to recovering. Histologically, the duodenum had inflammatory cell infiltrates and degenerate neurons in the myenteric plexus. Viallard et al. [6] presented a patient with thymoma-associated neuromyotonia, pseudo-obstruction and elevated titers of voltage-gated potassium channel antibodies who failed to improve with thymectomy and pyridostigmine. This patient underwent plasma exchange with resolution of the pseudoobstruction.

Our patient was unique in that he was seronegative. Negative tests included NAChR antibodies, voltage-gated calcium channel antibodies, type 1 antineuronal nuclear autoantibodies, ANA, ANCA, antiRo, anti-La, anti-double-stranded DNA, anti-RNP, Jo-1, anti-SCL-70, and antihistone antibodies. Voltage-gated potassium channel antibodies and anti-muscle specific tyrosine kinase receptor antibody titers were not obtained. We considered the diagnosis of ocular myasthenia gravis,

\section{KARGER}

Fax +4161306 1234 E-Mail karger@karger.ch www.karger.com (c) 2007 S. Karger AG, Basel 0014-3022/07/0582-0116\$23.50/0

Accessible online at: www.karger.com/ene
CPT David L. Greenburg, MD

Department of Medicine, EDP

4301 Jones Bridge Rd.

Bethesda, MD 20014 (USA)

Tel. +1 301792 1044, Fax +1 202782 5183, E-Mail dgreenburg@usuhs.mil 
as some improvement in diplopia was noted with anticholinergic agents. However, myasthenia gravis in patients with thymic hyperplasia is almost always associated with anti-N-AChR antibodies [7].

We hypothesized that our patient's ongoing pseudo-obstruction was a paraneoplastic phenomenon due to either circulating autoantibodies or chronic damage to the enteric nervous system $[5,8]$. If the former were true, he would potentially respond to immunomodulatory therapy. $\mathrm{He}$ had already failed high-dose corticosteroids. We considered plasma exchange and intravenous immunoglobulin (IVIG) because both therapies are effective in many neurological autoimmune processes $[9,10]$. We elected to treat with IVIG as our patient could be more easily retreated near his home if necessary. He received IVIG $2 \mathrm{mg} / \mathrm{kg}$ over 5 days starting on postoperative day 13. By postoperative day 22 , all symptoms were markedly improved, he was tolerating a regular diet, and a third gastric emptying study was normal. He was discharged on postoperative day 23 with instructions to continue pyridostigmine but discontinued it as he had minimal symptoms. Minor complications of IVIG included transient leukopenia and autoimmune thyroiditis [11]. Neither required therapy and both resolved spontaneously. Follow-up by telephone at 1 year revealed persistent resolution of all symptoms without further treatment. We hypothesized that his rapid recovery was due to IVIG-mediated accelerated clearance of pathogenic autoantibodies. To our knowledge, this represents the first use of IVIG to treat paraneoplastic thymoma-associated pseudo-obstruction. We feel IVIG should be considered as a potential treatment option for future cases of refractory thymoma-associated pseudo-obstruction.

\section{References}

1 Bogousslavsky J, Regli F, Doret AM, et al: Encephalopathy, peripheral neuropathy, dysautonomia, myasthenia gravis, malignant thymoma, and antiacetylcholine receptor antibodies in the CSF. Eur Neurol 1983;22: 301-306.

2 Tabbaa MA, Leshner RT, Campbell WW: Malignant thymoma with dysautonomia and disordered neuromuscular transmission. Arch Neurol 1986;43:955-957.

3 Kulling D, Reed CE, Verne GN, Cotton PB, Tarnasky PR: Intestinal pseudo-obstruction as a paraneoplastic manifestation of malignant thymoma. Am J Gastroenterol 1997;92: 1564-1566.
4 Takamori S, Hayashi A, Tayama K, et al: Improvement of dysgeusia after thymectomy with thymoma. Kurume Med J 1999;46:117118.

5 Anderson NE, Hutchinson DO, Nicholson GJ, Aitcheson F, Nixon JM: Intestinal pseudo-obstruction, myasthenia gravis, and thymoma. Neurology 1996;47:985-987.

6 Viallard JF, Vincent A, Moreau JF, Parrens M, Pellegrin JL, Ellie E: Thymoma-associated neuromyotonia with antibodies against voltage-gated potassium channels presenting as chronic intestinal pseudo-obstruction. Eur Neurol 2005;53:60-63.

7 Vincent A, Bowen J, Newsom-Davis J, McConville J: Seronegative generalised myasthenia gravis: clinical features, antibodies, and their targets. Lancet Neurol 2003;2:99-106.

8 Vernino S, Lennon VA: Autoantibody profiles and neurological correlations of thymoma. Clin Cancer Res 2004;10:7270-7275.

9 Bril V, Allenby K, Midroni G, O'Connor PW, Vajsar J: IGIV in neurology - evidence and recommendations. Can J Neurol Sci 1999;26: 139-152.

10 Natarajan N, Weinstein R: Therapeutic apheresis in neurology critical care. J Intensive Care Med 2005;20:212-225.

11 Matsuda M, Hosoda W, Sekijima Y, et al: Neutropenia as a complication of high-dose intravenous immunoglobulin therapy in adult patients with neuroimmunologic disorders. Clin Neuropharmacol 2003;26:306-311. 